\title{
CADÁVER TUERTO, DE EDUARDO LABARCA EN EL MARCO DE LA "NOVELA HISTÓRICA CHILENA RECIENTE"'
}

\author{
Corpse, de Eduardo Labarca under The "Historical Novel Recent Chilean"
}

\author{
Eduardo Barraza J.*
}

\section{Resumen}

Cadáver tuerto (2005) anticipa las variaciones del género novelesco en la literatura chilena, privilegiando y contemplando el proceso de la escritura. Labarca parodia en esta novela los cruces entre la ficción, la realidad y la historia, entre la vida y la autobiografía, entre el discurso televisivo, radial y del periodismo escrito, de modo tal que da un notorio giro discursivo a la narrativa chilena de filiación histórica

Palabras clave: Nueva novela histórica, narrativa chilena, metaficción historiográfica.

Abstract

Cadáver tuerto (2005) anticipates the variations of the novel genre in Chilean literatura, priviledging and contemplating the writing process. Labarca parodies, in this novel, the crossings among fiction and reality, between life and autobiography, between television, radio and written newsprint discourse.

Key words: New Historical Novel, Chilean Narrative, Historiographic Metafiction.

En el periodo comprendido entre la última década del siglo XX y la primera década del siglo XXI, se ha publicado un conjunto de textos que incrementan el corpus de la novela chilena de filiación histórica, incluso en su constancia pre-hispana. ${ }^{2}$ La guerra de Arauco y sus protagonistas indígenas y

${ }^{1}$ Este artículo forma parte del Proyecto de Investigación (Fondecyt Chile $\mathrm{N}^{\circ}$ 1085317): $\mathrm{El}$ discurso de la conquista: una serie textual autónoma de la narrativa chilena, en el cual participan, también, los académicos Pilar Álvarez-Santullano y Eduardo Castro Ríos.

${ }^{2}$ En Cielo de serpientes (2008) Antonio Gil incursiona en el mundo de la sacralidad precolombina; desde una escritura folletinesca - con un sesgo de feminismo- Isabel Allende actualiza la figura de Inés de Suárez en Inés del alma mía (2006), novela que establece una serie con respecto al tratamiento protagónico de la Conquistadora en Supay el cristiano (1967) y 100 gotas de sangre y 200 de sudor (1961) de Carlos Droguet y en Ay mama Inés (1993) de Jorge Guzmán. En El cementerio más hermoso del mundo (2008), la poesía de Cristian Formoso incursiona en la marca fundacional de Punta Arenas a partir de la fracasada empresa de Pedro Sarmiento de Gamboa, episodio que ya habían novelado Enrique Campos Menéndez (El caballero de la triste aventura, 1993) y Reinaldo Lomboy (Puerto del hambre, 1963). El teatro chileno presenta montajes recientes sobre Valdivia (Inés Stranger, 2009) y sobre Francisco Núñez de Pineda y Bascuñán (Compañía Tryo Banda, 2009) cuyo Cautiverio feliz fue editado íntegramente por Raissa Kordic (2001) y se constituyó en tópico central de un congreso convocado por la Universidad de Pamplona y la Universidad Católica de Santiago (junio, 2009). Isidora Aguirre ha hecho lo propio con la no afamada figura de Almagro (El adelantado don Diego de Almagro, 2000), texto que se suma a Crónica del Adelantado (1994), poemario de Enrique Volpe y a Hijo de mí (1992), novela de Antonio Gil, quienes también han escrito sobre este Conquistador. En 1989, 


\section{Eduardo Barraza}

españoles tales como Lautaro, Almagro, Valdivia, Inés de Suárez, Pedro Sarmiento de Gamboa, Francisco Núñez de Pineda y Bascuñán, son llevados a escena teatral, a la novela y a la poesía en un proceso escritural que enlaza con escrituras previas presentes en la literatura nacional (Subercaseaux, Aguirre, Droguett, Neruda). Se re-visita, también, el periodo colonial, ficcionalizando el poder implacable de la Inquisición, la fascinación o el rechazo que provoca la figura de la Quintrala, o el abolengo de Gobernadores y Corregidores. Otros textos representativos ficcionalizan episodios y personajes de la Independencia de Chile (O’Higgins), de la vida republicana del siglo XIX (Portales, Balmaceda) o las catástrofes político-sociales del siglo XX como aquellas de la Escuela Santa María de Iquique (1907) Ranquil (1934), el Seguro Obrero, (1938) y el quiebre y

Guillermo Blanco publica Camisa limpia, novela que reconstruye la institucionalidad inquisitorial, texto que se suma a El Inquisidor (2008) de Gustavo Frías quien, además, se ha propuesto escribir una trilogía sobre La Quintrala - proyecto que cuenta a la fecha con dos novelas: Catrala (2003) y La doña de Campofrío (2003) y Mercedes Valdivieso (Maldita yo entre todas las mujeres, 1991) - personaje colonial de interés novelesco-historiográfico, tanto como pueden serlo gobernadores y corregidores para la narrativa de Sady Zañartu (La sombra del corregidor ([1927]1999), de Jorge Inostrosa (El corregidor de Calicanto, 1960) y de Rodrigo Atria (Coplas de sangre, 1999). La serie folletinesca sobre la independencia de Chile está representada en el siglo XIX por Blest Gana con Durante la Reconquista (1897) y será continuada por Liborio Brieba al comenzar el siglo XX con sus Episodios Nacionales a fines del cual el foco de atención será la figura de O`Higgins (Juanita Gallardo, Déjame que te cuente, 1997 ), en tanto que la escritura laudatoria de los triunfos marciales la evocarán Daniel Riquelme (Bajo la tienda, 1883), El loco estero (1907) de Alberto Blest Gana y la extensa saga de Jorge Inostrosa (Adiós al Séptimo de Línea, 1958) a mediados del siglo XX. El protagonismo de Manuel Balmaceda será de interés narrativo para —entre otros- Juan Gabriel Araya (1891: entre el fulgor y la agonía, 1990); Darío Oses (El viaducto, 1994); Virgina Vidal (Balmaceda, varón de una sola agua, 1991) y José Agustín Linares (El último clarín, 1991) e Isidora Aguirre (2008), tanto como la figura de Portales lo es para Jorge Guzmán (La ley del gallinero, 1998) y Marta Blanco (La emperrada, 2001). Tampoco escapa la incursión narrativa al proceso derivado de la denominada "pacificación de La Araucanía (Juan Jorge Faundes, Viento de silencio, 1999); Guido Eytel (Casas en el agua, 1997). Los traumas político-sociales del siglo XX no son obviados por la literatura nacional, sean ellos los de 1907 ocurridos en la Escuela Santa María de Iquique (Santa María de las flores negras, 2002, de Rivera Letelier) o los sucedidos en Ranquil (novelados por Reinaldo Lomboy en Ranquil, novela de la tierra, 1942, y por Patricio Manns en Memorial de la noche, 1998) o escenificados por Isidora Aguirre en Los que van quedando en el camino (1969) o los acontecidos el año 1938 en el Seguro Obrero (Carlos Droguett, Sesenta muertos en la escalera, 1953; Guillermo Atías, A la sombra de los días, 1965; Fernando Alegría, Mañana los guerreros, 1964; Luis Enrique Délano, Al rumor de la batalla, 1964), así como los concernientes a la extensa serie que se constituye alrededor del quiebre y de la recuperación transicional de la democracia entre las décadas del 70 al 90. En suma, no se trata de agotar, aquí, las referencias a la literatura de filiación histórica, sino de hacer presente que tal narrativa ha dejado de ser mirada como una escritura al sesgo del canon de la literatura nacional y que, por lo mismo, merece ser re-visitada con un caudal teórico y metodológico adecuado que supere los tradicionales recuentos efectuados por Zamudio (1949) y Encina (1935), por ejemplo. 
Cadáver tuerto, de Eduardo Labarca

la recuperación transicional de la democracia entre las décadas del 70 al 90. Ahora bien, si extendemos este corpus textual hacia el tramo epocal que comprende el Bicentenario de Chile, resulta manifiesto que la ficcionalización de la historia en la literatura nacional exhibe una continuidad de diversos méritos textuales que permiten distinguir, de manera general, una literatura de filiación histórica tradicional (no necesariamente en los términos de Seymour Menton, 1993) y otra "reciente", según describe Antonia Viu (2007). Por ahora, basta para nuestro propósito esta breve introducción, pues nuestro objetivo es abordar el aporte que una novela como Cadáver tuerto de Eduardo Labarca hace a los procesos de innovación de las estrategias y procedimientos narrativos que requiere novelar la historia, reciente o pasada.

Hacia 1993, Seymour Menton designaba como "nueva novela histórica latinoamericana" una serie textual profusamente extendida en Hispanoamérica pero que, en su opinión, tendría escasos representantes en la literatura chilena. Disponer de un abundante corpus textual permitió, particularmente a Menton, caracterizar y sistematizar el canon constitutivo de esta textualidad narrativa y sus delimitaciones respecto a la llamada "novela histórica tradicional". A su vez, "novela chilena histórica reciente" es la denominación que —en el año 2007Antonia Viu postula como alternativa a la designación de S. Menton, noción con la cual aborda el estudio de 20 novelas chilenas —escritas entre 1985 y 2003 corpus que le permite incrementar las prescripciones de Menton y deslindar (para hacer visibles) otros aspectos teóricos y metodológicos de la nueva novela histórica en Chile, previstos —o no previstos - en los análisis de Fernando Ainsa (1997) y Fernando Moreno (1999), entre otros, en el marco de la reflexión latinoamericana sobre el tema.

Antonia Viu no se limita a un recuento bibliográfico de obras y autores representativos de la novela histórica en Chile, como en su momento hicieron Encina (1935) y Zamudio (1949), respectivamente. En su investigación, comienza planteándose el problema relativo a las fronteras y simbiosis entre "la historia, la ficción y la representación" para poner en discusión que se pretenda privilegiar un contrato de veridicción - antes que un pacto, convención o contrato narrativo- conforme al cual la "verdad, documentación y observación directa de los hechos" constituyen los criterios mediante los cuales la historia se define a sí misma distinguiéndose, así, de la ficción, de la fabulación, o de la "novelería", en que prima una convencionalidad, o contrato, entre narrador y lector con respecto al mundo representado (2007:34-35). Valiosas, al respecto, resultan las referencias teóricas que Antonia Viu rescata sobre esta discusión. Más allá de la clásica distinción de Aristóteles entre poesía e historia, Antonia Viu actualiza - entre otros - el pensamiento de Robin Collingwood (1946), quien —entre otras afirmaciones - sostiene que "La 


\section{Eduardo Barraza}

novela y la historia tienen que ser igualmente coherentes, nada es admisible en ninguna de ellas si no es necesario y el juez de esta necesidad es, en ambos casos, la imaginación" (En Viu, 2007:40), cuestión no distante de Barthes para quien la supuesta objetividad de la historia lleva consigo una ilusión historiográfica-referencial que puede ser desmontada recurriendo al análisis del discurso (1970). Esta ilusión factual que ya la advertía Arthur Danto (1965) cuando hace notar que la narración histórica no se limita a transmitir hechos, sino que los organiza e interpreta mediante el discurso, puesto que "lo fundamental de la historia no es transmitir una imagen o un conocimiento sobre el pasado tal y como ocurrió sino revestirla de significado, hacer que los acontecimientos del pasado revelen su sentido para el hombre contemporáneo... significado que no surge de la cercanía con el objeto sino... de la conciencia retrospectiva de intérpretes históricamente situados" (41. La cursiva es nuestra).

No obstante, para los efectos del estudio de la novela histórica $-\mathrm{y}$, en particular, el de nuestra lectura de Cadáver tuerto de Eduardo Labarca- la distancia temporal de la escritura con respecto a los hechos novelados constituye una de las piedras de toque de la discusión, tanto o más, como la cuestión de las fronteras entre la historia y la ficción. Publicada en el año 2005 (aunque presumiblemente terminada en el año 2002, Barraza, 2001:283) Cadáver tuerto se encuentra a más de treinta años de la década del Golpe Militar y su escritura resulta prácticamente contemporánea a los hechos, pues comprende desde antes de 1970 hasta el episodio de la detención de Augusto Pinochet en Londres durante 503 días (octubre 17 de 1998 al 3 de marzo del 2000, cuando regresa a Chile). Por lo mismo, resulta evidente que esta "contemporaneidad" a los hechos constituye uno de los componentes de "los yugos de la verdad" que pesa sobre la novela histórica, como ha planteado Karl Kohut (2001). El hecho es que la escritura de la novela histórica no se reduce a la simple conmemoración de efemérides y de figuras fundacionales de una nación, al modo de insignia, viñetas, retablos, inscripciones o semblanzas. Como precisa Viu (2007), el historial celebratorio está asociado, particularmente, a procesos de traumas y de conflictos colectivos que dejan tras sí una secuela de víctimas y de victimarios — de vencedores, vencidos y testimoniantes-; a tensos periodos de transición política y social. Al respecto ¿Por qué opta un novelista cuando se propone escribir una "novela histórica"? ¿Por ser un novelista o un historiador? ¿Por reconstruir un pasado recurriendo rigurosamente a fuentes, documentos, archivos y testimonios? ¿Re-construir ficcionalmente ese pasado examinando enciclopédicamente fuentes, documentos y testimonios históricos declarados al margen del discurso novelesco? ${ }^{3}$

\footnotetext{
${ }^{3}$ A juicio de Peter Elmore, "la pesquisa en bibliotecas y archivos no sólo precede a la redacción de las novelas, sino que en cierto sentido les sirve de garantía estética", aunque "el bagaje documental
} 


\section{Cadáver tuerto, de Eduardo Labarca}

¿Decidirse por una invención del pasado de manera que ocurra lo que efectivamente no ocurrió en la historia o ficcionalizar el pasado de manera que lo ocurrido aparezca como no sucedido? ¿Presentar el pasado como pudo ser y no fue?

El examen de opciones como las aquí propuestas permiten dar cuenta de la metalengua a la cual se ciñe la escritura de la "novela histórica", en general, $\mathrm{y}$, particularmente, la novela chilena del último tercio del siglo XX en torno al ciclo de la ruptura de la democracia y a su posterior recuperación, entre las cuales se cuenta Cadáver tuerto. Esta metalengua se expresa en los discursos complementarios de estas novelas, en sus epígrafes y dedicatorias, y en las auto-reflexiones críticas de los autores dadas en conferencias, ensayos y textos afines. A manera de ejemplificación, observemos algunas de estas modalidades, en diversas novelas de la década del 90.

Carrera, el húsar desdichado (1996) de Carlos Monge es subtitulado por su autor como "Fragmentos de un diario apócrifo", presuntamente escrito por el héroe "a quien la derrota no hizo menos grande", distanciamiento de la historia que se torna contradictorio cuando Monge sostiene que - aunque apócrifodicho texto "se postula como ficción pero respeta el severo rigor de los hechos históricos conocidos" (213-214). Tal afirmación traduce, internamente, un contrapunto entre discurso literario y discurso histórico presente en los sucesivos epígrafes histórico-científicos — de Francisco José Gall y Manuel Pueyrredóny literarios (Neruda, Whitmann) que se alternan en los sucesivos capítulos. ${ }^{4}$

Por su parte, Jorge Guzmán no acata esta conciliación entre historia y ficción, pues, en La ley del gallinero (1998) postula el privilegio de la ficción novelesca cuando advierte que "Todos los personajes y todos los acontecimientos que se leen en esta novela son ficticios, incluso los que a lo largo de los años pueden haber aparecido en libros de historia de algún país latinoamericano"; en tanto que, Antonio Gil en Cosa mentale (Santiago: Los Andes, 1994) pretende que la novela complete los vacíos de la historia, cuando sostiene que "Poco se sabe del mulato Gil de Castro, salvo el historiador Manuel Blanco Cuartín”.

remite menos a las exigencias del rigor académico que a la noción de un valor-trabajo añadido al texto por su productor" (1997:36). Sobre el particular uso que de las fuentes hace Eduardo Labarca en Butamalón (1994), a diferencia —entre otros- de Gabriel García Márquez en El general en su laberinto (1989, $8^{\text {a }}$ ed.) o, de Isabel Allende en Inés del alma mía (2006). Cfr. Eduardo Barraza. De La Araucana a Butamalón. El discurso de la conquista en la literatura chilena. Valdivia: Universidad Austral de Chile. Anejo No 17 de Estudios Filológicos, 2005.

${ }^{4}$ Eduardo Labarca. Cadáver tuerto. Santiago: Catalonia, 2005:13. Citaremos por esta edición. El respeto de Carlos Monge por el severo rigor de los hechos históricos conocidos lo lleva a agregar un "post-facio" acerca de "la suerte corrida por los personajes", muy al modo del verosímil de la novela realista. 


\section{Eduardo Barraza}

En Los años de la serpiente (1991), Antonio Ostornol, luego de relatar a su hija los traumáticos sucesos del 73 —en una carta que luego de enviada a Chile desde París no puede recuperar- pretende des-escribir tales sucesos, confesándole: "debo inventar, querida hija, un final feliz para esta historia". Ésta es una perspectiva que difiere de Jorge Montes quien en El 73 (1994) postula una novela referencial en tanto sumatoria de documentadas escrituras menores, por cuanto, declara "Recibí en el exilio no pocas cartas conteniendo relatos, vivencias...en este libro tienen la respuesta... querían nada más que sus hechos no fueran olvidados de la memoria chilena" (217).

\section{HISTORIA-FICCIÓN: “ALLENDE LOS LÍMITES"}

Cadáver tuerto ha sido leída, preferentemente, como la puesta en práctica de un discurso referencial de carácter historiográfico (la detención de Augusto Pinochet en Londres), postergándose el proceso de su ficcionalización en esa Fábula del juez perseverante, el cirujano concienzudo y general desconfiado. A este recurso se suma la puesta en práctica de una estrategia literaria, como lo es el "cadáver tuerto", de la vanguardia. De esta forma, Lautraro - el protagonista - no sólo da cuenta de su peripecia social-utópica sino que igualmente, en su calidad de autor, actor e intérprete de su mundo descubre "cómo la realidad rompe sus últimas fronteras" (341).

El hecho es que, a excepción de su título, Cadáver tuerto aparenta carecer de discursos des-ambiguadores que orienten sobre el modo como se procede para que — según se ha dicho- los acontecimientos de las tres últimas décadas del siglo $\mathrm{XX}$ revelen su significado para los lectores e intérpretes históricamente situados. No obstante $-\mathrm{y}$ no sin polémica- esta novela ha sido leída al margen del hecho de que la narración referida a este conflictivo periodo histórico de Chile no se limita a transmitir tales episodios, sino que los organiza e interpreta mediante el discurso, puesto que lo fundamental en ella no es proporcionar una imagen o un conocimiento sobre el pasado reciente - tal y como ocurrió- sino revestirlo de significado, hacer que esos acontecimientos revelen su sentido para el hombre contemporáneo, significado que no surge de la cercanía con el objeto sino... de la conciencia retrospectiva de intérpretes históricamente situados ( $C f r$. Danto, en Viu 2007: 41).

Nunca he podido tragar a los escritores que adoptan aires académicos, dan clases de literatura, escriben crítica literaria y pontifican en simposios y seminarios, generalmente con sangre en el ojo y mala leche sobre las obras de sus colegas. Dejemos los simposios a los académicos y nosotros, escritores, dediquémonos a escribir para que ellos, a su vez, tengan algo de qué escribir, sobre todo, de qué hablar en los simposios (1999:431) 
confiesa Labarca —en un Congreso sobre la literatura chilena y la difícil transición a la democracia celebrado en Austria- pero no es menos cierto que en su ponencia terminará dando cuenta de las premisas que rigen su escritura. Entre estas premisas están las relaciones entre la historia y la novela al modo de un contrapunto, de una libertad e independencia del novelista respecto al historiador como expuso en un congreso anterior (1995). En la ocasión —a propósito de Butamalón, que acababa de terminar- contempla ambas discursividades concluyendo que "el historiador hace historia" y "el novelista hace novela" a partir del material del historiador, estableciéndose entre ellos un enlace, a veces, mediante "un nudo grueso y otras mediante un nudo invisible", según explicitará, posteriormente, al referirse a Cadáver tuerto en la Feria Internacional del Libro de Santiago de Chile el año 2005, apelando a que su "novela sea leída de una vez por todas como tal" y no sea reducida a la polémica que suscitó su revelación de haber escrito el Diario apócrifo del General Carlos Prats. ${ }^{5}$

En "Cómo escribir un best seller en el siglo veintiuno" — un ensayo de "poética-ficción" presentado al Congreso en referencia- Eduardo Labarca sintetiza y expone sus ideas sobre la autonomía del novelista frente a la historia que novela. En esta fábula — soslayadamente referencial- ${ }^{6}$ uno de los "talleristas", o aprendiz de escritor se define por la ficcionalización del mundo y de la historia (1999:437).

Y tal "sacralización" del espacio privado del fabulador deriva en una radical "de-sacralización" de la historia que efectúa el novelista, frente a la "sacralización" de la historia que postula el historiador. El "novelista novelado" -en el "diario" a que hacemos referencia- refiere que su proyecto es escribir "una novela histórica en clave metadiegética", en la que el teatro sirva de marco a la narración. Se trata de escribir

La gran novela que falta de Salvador Allende. Tiene la forma de una ópera salsa que se va creando y representando a lo largo del libro: Allende, la Tencha, la Payita, Pinochet... "se va escribiendo y representando en presencia de Allende, dentro de la novela cuyo protagonista es Allende, quien después de muerto se está viendo a sí mismo, o sea a Allende" (1999:436).

\footnotetext{
${ }^{5}$ Tal hecho provocó una intensa cobertura periodística. Para un enfoque analítico. $C f r$. Ariel Carabantes. El discurso testimonial: Paradigma crítico de la memoria chilena en la obra de Carlos Prats. (2006). Tesis para optar al título de Profesor de Lengua Castellana y Comunicaciones. Osorno: Universidad de Los Lagos (Patrocinada por el autor de este artículo). ${ }^{6}$ Géneros referenciales son "aquéllos donde al revés de lo que ocurre en los géneros ficcionales como la novela, autor y sujeto de enunciación (o "narrador") coinciden: son el mismo". Leonidas Morales. La escritura de al lado. Santiago: Cuarto Propio, 2001:11.
} 


\section{Eduardo Barraza}

Vale decir, más que una fórmula de best-seller se trataría de una contrafórmula, ${ }^{7}$ pues se pretende desestabilizar también el género de la novela que llevará en su interior - como fórmula triunfadora - su doble paródico: el carnaval, lo grotesco, el teatro y los géneros televisivos (radioteatro, series policiales, comics, comerciales, el reality, avisos subliminales) como ocurre en Cadáver tuerto, con todos los riesgos de recepción al postular la autonomía de lo literario frente a la historia. El "tallerista" aludido tiene clara conciencia de su transgresión.

Mi novela des-contruye Allende y carnavaliza su gobierno, y la familia Allende me va a quitar el saludo. La novela no endiosa a Allende y los allendistas me van a acusar de vendido. Cuando vean a Pinochet con un uniforme cubierto de plumas, los milicos me van a acusar de traidor a la Patria. Voy a quedar peleado con todo el mundo y sin poder volver a Chile quizás hasta cuándo. Pero a cada cual le contestaré: "¡Alto, compadre; alto, comadre!" Ficción: el sagrado derecho del autor a fabular y mentir que reconoce el mismo Aristóteles (1999:437).

Pero, Cadáver tuerto no es la novela sobre Salvador Allende que describe este "aprendiz de novelista" — quien, finalmente, triunfa con su proyecto, aunque debe ocultarse bajo un seudónimo - sino sobre el Golpe Militar de 1973 y sobre su epílogo factual relativo a la detención de Augusto Pinochet en Londres, pero en ella se llevan a cabo los principios de esta "descontrucción" y "carnavalización de la historia" que se nos anticipa, y los efectos polémicos de una propuesta de escritura que sustenta "el sagrado derecho de la ficción" entendida como "mentirosa fabulación de la historia"

Por su naturaleza el discurso ficcional es plurisémico y equívoco - hace constar Fernando Ainsa - aunque intente ser persuasivo y convincente al modo histórico. En todos los casos, trata de reproducir - como anticipa Barthes - un "efecto de realidad", una "ilusión referencial" conforme al principio aristotélico de la Poiesis: la mimesis de la realidad. Lo cotidiano, lo inmediato se incorpora a la ficción, por lo cual el cosmos novelístico se hace realista y verosímil. Ello permite hablar de "estrategias de persuasión", entre las que destaca la ilusión de mimesis del diálogo o del monólogo. El historiador habla de lo que sucede, no lo re-produce ni trata de hacerlo, mientras que la ficción se presenta como "realidad"

\footnotetext{
${ }^{7}$ Resulta notorio que, habiendo sido premiada por el Consejo Nacional del Libro y la Lectura como Mejor Novela del año 2005, Cadáver tuerto haya despertado escaso interés crítico. Entre las excepciones se cuenta una reseña de Ewald Weitzdörfer en Alpha $\mathrm{N}^{\circ} 23$ (Diciembre, 2006):309310. Salvo que demos por sentado que se haga extensiva a la narrativa la fórmula que sostiene Sancho Martínez: "La televisión es imagen y me quieres vender literatura. A nadie le va a interesar una sesión de escritura ni menos de lectura. Yo necesito teatro y suspenso en la pantalla: tiros, cachas y pechugas de silicona" (270-271), premisa ya anticipada por el "aprendiz de novelista".
} 


\section{Cadáver tuerto, de Eduardo Labarca}

a través de las voces múltiples del discurso dialógico que la caracteriza" (Ainsa, 1997:118).

Para el caso de la novela histórica, puede considerarse que ese "efecto de realidad", esa "ilusión referencial" — que advierte Barthes — se manifiesta como un "efecto textual de ilusión historiográfica" ${ }^{8}$ proveniente de un singular "tipo lógico específico" que rige al discurso narrativo. Félix Martínez Bonati" recuerda que en su De interpretatione, Aristóteles describe las "frases apofánticas, como aquéllas capaces de expresar juicios en los cuales reside la falsedad y la verdad al mismo tiempo" (1972:56); aquéllas "en que la forma linguística propia del juicio no se acompaña de la intención de dar por sentado - de afirmar- lo que se enuncia, esto es, de pretender su verdad. Se puede "enunciar - agrega Martínez Bonati- como mero despliegue de un pensamiento posible de expresar por medio del lenguaje" (57). Y este "pensamiento posible de expresar - ficcionalmente acerca de la historia- por medio del lenguaje" es lo que demandan las convenciones del texto novelesco para ser tal

"En literatura — enfatiza Martínez Bonati- la imagen-imitación tiene su sentido, su razón de ser en sí misma, no vale por eventual aplicabilidad a particularidades del mundo real, sino por sí misma como imagen. Por ello es indiferente que pueda o no realizarse la mimesis literaria como historiográfica (que pueda leerse la narración como documento histórico) se trata de otro plano, ajeno a la esfera y el interés estéticos" (73).

Y todo ello ocurre porque — según Martínez Bonati- "el mundo narrado se constituye ante nosotros como el narrador, en frases miméticas dice que es" (71), para nuestro caso, trátese del discurso de la historia o de la ficcionalidad literaria, salvo que se proceda al desmontaje de la convencionalidad del pacto de lectura —entre lector y narrador - respecto a la verosimilitud que rige el mundo narrado.

\footnotetext{
${ }^{8}$ A manera de hipótesis de trabajo, este "efecto de historicidad" podría ser asimilable al "efecto de realidad" que plantea Roland Barthes. (1993). Cfr. Una propuesta mía en este sentido en "De Gobernadores y vecinos en el Reino de Chile en un corpus epistolar y textual de los siglos XVI y XVII". Arica: Universidad de Tarapacá: Actas Seminario Internacional de Estudios Literarios (SOCHEL), 2006, y en "El Erasmo y el Virgilio inútiles en El hambre, cuento de Manuel Mujica Laínez", en Cuadernos Americanos. 2007:163-171.

9 "La espontánea atribución de validez al discurso mimético del narrador, y la correspondiente jerarquía de la prioridad lógica — continúa Martínez Bonati- son una convención constitutiva de la narración como objeto, una forma o principio trascendental de la comprensión o experiencia de narraciones"... "la frase tenida por verdadera es la que hace posible el mundo imaginado, la que, al establecer como algo que así es o ha sido a la imagen que proyecta, hace presuntamente visible un aspecto de configuración del mundo. Atribuir verdad a una frase dando crédito al hablante, es proyectar en imagen un aspecto del mundo..." (1972:70).
} 


\section{Eduardo Barraza}

Tal des-montaje o desarticulación del pacto narrativo es uno de los modos como en Cadáver tuerto se llevan a cabo - entre otros-los principios de "des-contrucción" y "carnavalización de la historia" que postulaba el "aprendiz de escritor". El lector ingresa a la convencionalidad del mundo narrado que "se constituye ante nosotros como el narrador —en frases miméticas- dice que es". Tal ocurre en la escena de apertura, de la Visión Primera, titulada Allende los límites (9-13) cuando el narrador nos sitúa como espectadores de una secuencia en la cual un "Juez" se dispone a firmar una orden de captura contra un acusado que ha perseguido por más de cinco años y a quien conoce "como a un pariente cercano" "a pesar de no haberlo visto nunca" (9). Guiado por la segura "voz" aseverativa del narrador, según cuyas frases miméticas, el mundo es tal como él dice que es - enfatizamos- el lector desprevenido no advierte los sutiles componentes no referenciales que se van apoderando del mundo narrado: nominación de personajes, lugares y eventos mediante designaciones genéricas escritas con mayúsculas, vacíos o exigencias que el lector puede llenar con aparente facilidad, por su competencia extratextual: el nombre del Juez, el de un General en Jefe, el de un País que se cae del mapa; un Reino de eterna llovizna, un Cirujano emérito, la Operación Sol Naciente. En suma, se trata de no acoger "con reservas" las frases afirmativas del narrador, puesto que si así ocurriera (según advierte Martínez Bonati) una narración de esta índole estaría "inhibida para fundar mundo; (pues) la imagen que propone queda incierta, insubstancial, porque no recibe la adhesión de una conciencia plena" (1972:70).

Vale decir, el pacto narrativo exige la primacía del narrador por sobre el lector. Sólo por excepción —en un acto de lectura convencional- se podría llegar a conceder: "Admito que, ya en ese primer párrafo, hay ciertos desajustes entre la realidad y la ficción" (82) como deduce y cuestiona el inquisitivo e impertinente lector de "El autor de La caza del lobo" de Denevi (1973:82). El contrato de lectura prescribe (en letra chica, tal vez) que el lector no debe polemizar respecto al modo como el narrador dice que es el mundo que le narra. Lo transgresor, en Cadáver tuerto, ocurre porque (seducido por las palabras del narrador) el lector no advierte el carácter privativo, no consabido - ni pre-figurado como conocimiento anterior- que va adquiriendo el mundo convocado por el narrador que lo conmina (lo desafía, más bien) a percibirlo como "realidad verbal antes que como denotación referencial". Basten como ejemplos —en la primera secuenciael lugar protagónico que ocupa el acto de "escribir-firmar", la orden de captura, ${ }^{10}$ escritura-inscripción que finalmente se traza agresivamente en el

${ }^{10}$ El episodio recuerda un procedimiento similar en Yo, el Supremo (1974) de Augusto Roa Bastos (1987). 
"cuerpo" del enfermo General en Jefe; la hibridación entre lo judicial y lo filial cuando el Juez rememora a su madre; la carnavalización de una operación quirúrgica que termina reproduciendo inversamente una escena de tortura no ocurrida en la "historia", pero que se escenifica ante un lector que se ha creado expectativas historizantes con respecto a la novela. Finalmente, como si todo lo anterior no bastara - en un gesto de metalepsis- el narrador desenmascara ante el lector la condición ficticia del mundo narrado: la historia que lee es un acto verbal. Nada más ni nada menos que una emisión radial al modo de un radioteatro; lo que está leyendo es lo que relatan unos locutores a sus auditores de un programa radial, puesto que en un gesto perlocutivo des-incantatorio proclama "Y así, queridas auditoras y amigos auditores de Escucha Allá, termina la Fábula del juez perseverante, el cirujano concienzudo y el general desconfiado" (13).

Cadáver tuerto desestabiliza, así, uno de los estatutos de la novela: ella no tiene por qué declarar que es ficción. Y, si así ocurriera, tal afirmación está mediada por el recurso a las implicaturas de que hace gala el lector, a partir de las cuales las claves de simbolización son decodificadas fuera de lo dicho, en un contexto no apofántico (sé quién es ese Juez, quién es ese General, etc.), contrapunto de lectura que se apodera de la novela. El radioteatro no encubre su condición de mundo al revés, pues reproduce tanto un hecho histórico - detención de Augusto Pinochet en Londres- como lo que pudo ocurrir pero no ocurrió al respecto: el torturador torturado.

El examen de este texto radiofónico establece un estatuto de variados registros textuales en la novela: $\mathrm{La}$ "fábula" responde a un género narrativo menor a la novela; exhibe sin enmascaramientos su carácter de ficción respecto a la "historia"; tipifica a sus personajes y actúa como relato de segundo grado sobre el final de la historia de un victimario, de manera que la novela que leeremos puede considerarse como el relato básico, real, anterior, histórico (no ficticio), relativo a víctimas y/o sobrevivientes, como es el caso de Eleuterio-Lautraro, un actor aficionado que recuerda su adhesión a la Unidad Popular y su posterior exilio. El programa Escucha Allá establece un dialógico pacto de verosimilitud: sitúa en un "Acá" foráneo la voz de exiliados que, aunque relegados en un "acá" extranjero "saben" lo que "ignoran" —o no pueden decir- quienes permanecen en su "acá original". Además, tal programa radial no transmitía, precisamente, textos literarios ni menos a la altura de la "fábula" que aparece reproducida en las primeras páginas de la novela (Teitelboim, 2001). Por otra parte, las emisiones de este programa concluyeron con anterioridad al episodio de Londres y, menos, el desenlace presentado por la fábula sucedió tal como allí se describe. En suma, la "fábula" presenta la posibilidad de que la historia haya ocurrido en los términos que ella relata; actúa como prolepsis, proporcionando un final anticipado —o deseado— de la novela que se leerá a 


\section{Eduardo Barraza}

continuación. Constituye un leit motiv emblemático que sintetiza alegóricamente una historia y su respectiva moraleja y ha sido entendida de este modo por cuanto circula profusamente y hasta ha sido traducida al rumano (...) y no está exenta de continuos procesos de reescritura que concluyen cuando aparece siendo reproducida en las páginas de El Macuto, diario principal de la Capital del País Lejano al cual ha regresado Lautraro. Nótese, además, que el episodio de la historia nacional que debía ser resuelto en el País lejano ("Acá originario") ha sido puesto en escena en los Tribunales de un Reino Lejano ("Allá") por actores y jueces extraños a la historia vivida en el País que se cae del mapa. No obstante, este exótico escenario permite observar a distancia una mise en scene carnavalesca de la historia nacional, que procede a reactivar a los bandos protagónicos. En suma, en Cadáver tuerto la ficcionalización de la historia llevada a cabo como discurso literario - que pre-supone un desenlace imaginado para una "historia realmente acontecida" - reclama que se narre el epílogo, posfacio, o desenlace del General en Jefe, tal como sucedió en Londres y se vivió en Chile.

Entre el 16 de octubre de 1999 y más allá del 3 de marzo del año 2000, las estrategias transicionales del retorno a la democracia sufrieron una recia acción desestabilizadora "a través de múltiples flujos de expresividad contestataria" -que entre otros efectos- "descompaginó el libreto de la actualidad televisiva nacional" y puso a la vista la vigencia latente de los bandos protagónicos de la pérdida y la recuperación de la democracia, como acota Nelly Richard. ${ }^{11}$ En lo particular, reactivó la palabra perdida, domesticada, el "no decir", expresión a la que recurre Andrea Maturana para dar título a una serie de once cuentos. A esta "actividad de la memoria resuelta a deshacer y rehacer los procesos de evocación y narración del pasado", es a lo que invita Cadáver tuerto, recurriendo —entre otras estrategias- a un discurso alegórico, propio del género de la fábula.

Universidad de Los Lagos* Departamento de Humanidades y Arte Casilla 933 - Osorno (Chile) ebarraza@ulagos.cl

\footnotetext{
${ }^{11}$ Nelly Richard. Fracturas de la memoria. Arte y pensamiento crítico. Buenos Aires: Siglo Veintiuno, 2007:180. El texto reúne una selección de artículos que la autora ha publicado hasta la fecha. Para nuestro propósito. Cfr. "Las mujeres en la calle (con motivo de la captura de Pinochet en Londres en 1998)" (153-168); "Las marcas del destrozo y su reconjugación en plural” (169-184) y "El fragmento errático de una actuación en los bordes" (185-195).
} 
Cadáver tuerto, de Eduardo Labarca

\section{BIBLIOGRAFÍA}

ACEVEDO, Rafael. Exquisito Cadáver. Puerto Rico: El Callejón, 2001.

AINSA, Fernando. "Invención literaria y reconstrucción histórica en la nueva narrativa latinoamericana", en Kart Kohut (Editor). La invención del pasado. La novela histórica en el marco de la postmodernidad. Frankfurt-Madrid: Vervuert, (1995) 1997:111-121. Actas Encuentro de Escritores Iberoamericanos en Viena. Instituto Austríaco para América Latina, en colaboración con la Sociedad Colombo-Austríaca (1993-1995). Publicaciones del Centro de Estudios Latinoamericanos de la Universidad Católica de Eichstätt.

BARRAZA, Eduardo. "El Erasmo y el Virgilio inútiles", en El hambre, cuento de Manuel Mujica Laínez, en Cuadernos Americanos, 2007.

"De Gobernadores y vecinos en el Reino de Chile en un corpus epistolar y textual de los siglos XVI y XVII". Arica: Universidad de Tarapacá: Actas Seminario Internacional de Estudios Literarios (SOCHEL), 2006.

------ De la escritura de rebeliones a la rebelión de la escritura. El discurso de la conquista en la literatura chilena. Valdivia: Universidad Austral de Chile 2002.

------ De La araucana a Butamalón. El discurso de la conquista en la literatura chilena. Anejo $\mathrm{N}^{\circ} 17$ de Estudios Filológicos. Valdivia: Universidad Austral de Chile, 2005.

BARTHES, Roland. "L’effet de réel", en Le bruissement de la langue. Essais critiques III. Paris: Points-Essais, 1993.

CARABANTES, Ariel. El discurso testimonial: Paradigma crítico de la memoria chilena en la obra de Carlos Prats. Tesis para optar al título de Profesor de Lengua Castellana y Comunicaciones. Osorno: Universidad de Los Lagos, 2006.

DENEVI, Marco. "El autor de La caza del lobo", en Antología precoz. Santiago: Universitaria, 1973.

ELMORE, Peter. La máquina de la memoria. La crisis de la representación en la novela histórica latinoamericana. Lima: F.C.E., 1997.

EMAR, Juan. Umbral. Primer pilar. El globo de cristal. Tomo I. Buenos AiresMéxico: Carlos Lohlé, 1977.

HUIDOBRO, Vicente. "Non serviam". Manifiesto leído en El Ateneo (1914), en Obras completas. Santiago: Zig-Zag, 1964.

KOHUT, Karl (Editor). La invención del pasado. La novela histórica en el marco de la postmodernidad. Frankfurt-Madrid: Vervuert, (1995) 1997:111-121. Actas Encuentro de Escritores Iberoamericanos en Viena. Instituto Austríaco para América Latina, en colaboración con la Sociedad Colombo-Austríaca (19931995). Publicaciones del Centro de Estudios Latinoamericanos de la Universidad Católica de Eichstätt.

------- ¿Bajo el yugo de la verdad? La novela histórica entre verdad e imaginación. (Conferencia). Göettingen (2001) febrero 8.

KOHUT Karl; MORALES SARAVIA, José (Eds.). Literatura chilena hoy. La difícil transición. Actas simposio Literatura chilena hoy. La difícil transición. Febrero 24-27 (1999). Frankfurt/Main - Madrid: Vervuert, 2002:431-444. 


\section{Eduardo Barraza}

LABARCA, Eduardo. "La realidad histórica emergiendo de la ficción". 25 2 Feria Internacional del Libro de Santiago. (Noviembre, 2 de 2005).

Cadáver tuerto. Santiago: Catalonia, 2005.

------ "Cómo escribir un best seller en el siglo veintiuno", en Karl Kohut y José Morales Saravia. (Eds.). Literatura chilena hoy. La difícil transición. Actas simposio Literatura chilena hoy. La difícil transición. Febrero 24-27 (1999). Frankfurt/Main - Madrid: Vervuert, 2002:431-444.

------ Acullá. Santiago: Documentas, 1990.

MARTÍNEZ BONATI, Félix. La estructura de la obra literaria. Barcelona: SeixBarral, 1972:70.

MATURANA, Andrea. No decir. Santiago: Alfaguara, 2006.

MENTON Seymour. La nueva novela histórica en América Latina. México: F. C. E., 1993.

MORALES, Leonidas. La escritura de al lado. Santiago: Cuarto Propio, 2001:11.

MORENO Fernando. "Apuntes en torno a la tematización de la Historia en la narrativa chilena actual", en Karl Kohut y José Morales Saravia. (Eds.). Literatura chilena hoy. La difícil transición. Actas simposio Literatura chilena hoy. La difícil transición. Febrero 24-27 (1999). Frankfurt/Main - Madrid: Vervuert, 2002:271- 278.

RICHARD, Nelly. Fracturas de la memoria. Arte y pensamiento crítico. Buenos Aires: Siglo Veintiuno, 2007.

ROA BASTOS, Augusto. Yo, el Supremo (1974). Madrid: Siglo Veintiuno, 1987.

RODRÍGUEZ, Mario; TRIVIÑOS, Gilberto. (Eds.). Utopía y mentira de la novela panóptica. Concepción: Universidad de Concepción, 2006.

TEITELBOIM, Volodia. Noches de radio (Escucha Chile) II. Una voz viene de lejos. Santiago: Lom, 2001.

VIU, Antonia. Imaginar el pasado, decir el presente. La novela histórica chilena (1985-2003). Santiago: RIL, 2007. 